\title{
Reflex inhibition in humans: Sensitivity to brief silent periods in white noise
}

\author{
JAMES R. ISON \\ University of Rochester, Rochester, New York \\ and \\ LINDA A. PINCKNEY \\ Nazareth College, Rochester, New York
}

\begin{abstract}
A white noise (60 dB SPL) was always present except for brief silent periods ("gaps") which occurred just before an eyelid reflex was elicited in human volunteers by a brief innocuous shock to the forehead. In Experiment 1 (n=8), 10-msec gaps ("S1") were given 40, 80, 120, 160, or 200 msec before the shock ("S2"). Compared with S2-alone trials, the reflex was inhibited by about $50 \%$ at intervals of $80 \mathrm{msec}$ and beyond. Experiment $2(n=12)$ first provided detection thresholds for gaps using a simple version of the method of limits: on average a gap of $5.4 \mathrm{msec}$ duration was just detected. Then gaps of $0,2,4,6,8$, and 10 msec were given in random order, each $100 \mathrm{msec}$ before S2. The 4-msec stimulus was an effective inhibitor of the reflex, and inhibition further increased on to 6- and then to 8-msec durations. A comparison of the values obtained on reflex inhibition with the 5.4-msec threshold obtained with the conventional psychophysical test reveals that in humans reflex inhibition provides an objective index of stimulus detection that is at least of sufficient sensitivity to warrant its clinical application. The steady increase in reflex inhibition as gap duration increased from 2 to $8 \mathrm{msec}$ may be of significance for tracing the rate of decay of afferent stimulation following noise offset, as it presumably reflects the growing sensitivity to the resumption of the noise as the duration of the silent period is increased.
\end{abstract}

The present experiments are concerned with whether brief silent periods ("gaps") in an otherwise steady noise background affect cutaneous eyeblinks elicited shortly after their occurrence and, then, how the sensitivity of the reflex control system to these preceding acoustic transients might compare with detection thresholds obtained by a simple psychophysical method. We know that cutaneous eyeblink reflexes in humans, like some other reflexes in humans and other species, are sensitive to seemingly extraneous perturbations in the sensory surround which accompany or briefly precede reflex elicitation (Bowditch \& Warren, 1890; Cohen, Hilgard, \& Wendt, 1933; Dykman \& Ison, 1979; Graham \& Murray, 1977; Graham, Putnam, \& Leavitt, 1975; Hilgard \& Wendt, 1933; Hoffman \& Stitt, 1980; Ison \& Pinckney, 1980; Krauter, Leonard, \& Ison, 1973; Lombard, 1887; Marsh, Hoffman, \& Stitt, 1976,

This work was supported by research grants from the Public Health Service, ES 01248, and from the Environmental Protection Agency, R-8068201. Although this work was supported in part by the Environmental Protection Agency, it has not been subjected to the Agency's required peer and policy review. Therefore, it does not reflect the views of the Agency, and no official endorsement should be inferred. Reprint requests should be sent to James $R$. Ison, Psychology Building, University of Rochester, Rochester, New York 14627.
1978; Reiter \& Ison, 1977, 1979; Sanes \& Ison, 1979). The effectiveness of the leading stimulus event in controlling reflex expression is determined in part by the lag time between it and the subsequent reflexeliciting stimulus and in part by its intensity (Hoffman \& Ison, 1980). When the interstimulus interval approximates $100-200 \mathrm{msec}$, the reflex is maximally inhibited in humans, and the amount of inhibition is a direct function of lead stimulus intensity.

For pulses of white noise, stimulus intensities that approximate the sensory threshold as defined by a simple psychophysical test have a reliable effect on reflex expression (Reiter \& Ison, 1977). Furthermore, the magnitude of reflex inhibition is reported to be linearly related to stimulus intensity (measured in decibels) and to log stimulus duration (in seconds) over a considerable part of a range of intensities and durations (Dykman \& Ison, 1979; Hoffman \& Searle, 1968; Reiter \& Ison, 1977). The detection of gaps in white noise must depend in part on the decay in neural activity following noise offset (Plomp, 1964). If reflex expression is sensitive to the presence of gaps in white noise, then the quantitative detail of the function relating its inhibitory effect to gap duration may be informative about the temporal course of auditory decay. 


\section{EXPERIMENT 1}

With noise pulses or light flashes, maximum reflex inhibition is found at intervals approximating 100 $200 \mathrm{msec}$. Inhibition increases rapidly as this interval is approached from below, then declines slowly with further increases in the lead time. In this first experiment, we chose a gap duration that all subjects should have been able to detect and varied the lead time between that gap and the reflex-eliciting event.

\section{Method}

Subjects. Eight adults were used, six women and two men, who responded to a request in an advanced psychology course for volunteer subjects. None had any hearing impairment or known neurological deficit.

Apparatus. The subject sat comfortably in a lounge chair housed within a double-wall sound-attenuating chamber (IAC), approximately $3.6 \times 2 \times 2 \mathrm{~m}$. The acoustic signal was formed by a white-noise source constructed at the University of Rochester, gated through an electronic switch, amplified, and delivered into the right side of a pair of TDH-39 earphones. Electrotactile stimuli were used to elicit the eyeblink reflex. They were provided by a Grass biomedical stimulator and constant-current unit (SD5 and CCU1), delivered to the forehead via two surface electrodes (Beckman miniature $\mathrm{Ag} / \mathrm{AgCl}$ ). Stimuli were timed by a bank of electronic timers constructed at the university. Responses (EMG) were detected by two other Beckman miniature electrodes gummed over the orbicularis oculi muscles, with a ground electrode at the temple. Electromyographic activity was fed through FET preamplifiers to Grass differential amplifiers with half-amplitude settings of $10 \mathrm{~Hz}$ to $75 \mathrm{kHz}$. The EMG response was observed on a storage CRT, and then measured by being rectified and integrated over a 50 -msec time period beginning about $30 \mathrm{msec}$ following the eliciting stimulus. (Responses were never seen to occur to the gap in the noise.) Variation in starting time for the recording epoch depended on individual differences in the subject's response latencies. The response size was read as a voltage on a digital voltmeter.

Procedure. The subject was given a general description of the recording and stimulating methods to be encountered, on a standard consent form. Given the subject's agreement to continue in the experiment, the sites of attachment of the five electrodes were cleaned following standard procedures. Two electrodes were placed over the path of the right supraorbital branch of the trigeminal nerve about 1 and $2 \mathrm{~cm}$ above the eyebrow, the cathode being proximal. Two electrodes were placed over the right orbicularis oculi muscles, one at the outer canthus and one about $1 \mathrm{~cm}$ below and medial to it. The ground was placed at the temple between stimulating and recording electrodes. Impedences were below $10 \mathrm{k} \Omega$. Following electrode placement, the subject was escorted into the experimental chamber, electrodes were attached to the apparatus leads, and the earphones were put on. A white noise of $60 \mathrm{~dB}$ intensity (SPL re $20 \mu \mathrm{N} / \mathrm{m}^{2}-\mathrm{A}$ scale) was continuously present except for just before designated trials. The intensity of the noise across various frequencies was, at $31.5 \mathrm{kHz}, 40 \mathrm{~dB} ; 16 \mathrm{kHz}$, $48 \mathrm{~dB} ; 8 \mathrm{kHz}, 50 \mathrm{~dB} ; 4 \mathrm{kHz}, 57 \mathrm{~dB} ; 2 \mathrm{kHz}, 55 \mathrm{~dB} ; 1 \mathrm{kHz}, 55 \mathrm{~dB}$; $500 \mathrm{~Hz}, 55 \mathrm{~dB} ; 250 \mathrm{~Hz}, 54 \mathrm{~dB} ; 125 \mathrm{~Hz}, 52 \mathrm{~dB} ; 62 \mathrm{~Hz}, 52 \mathrm{~dB}$, as given by a $B$ \& $\mathrm{K}$ sound-level meter with external filter.

In order to maintain a constant and reasonably alert state in the subjects, they were asked to read silently during the conduct of the experiment, from a selection of magazines and books provided for them. The subject's behavior was monitored over TV, and trials were withheld if the subject was turning pages or otherwise responding in a way that might affect reflex expression (for example, yawning). The subject was asked to blink several times (assuring us that response recording was working), and cutaneous thresholds were taken using three series of the ascending method of limits. Then, as the subject read, the intensity of the eliciting stimulus was increased from trial to trial, giving a trial once every $20-40 \mathrm{sec}$, until reliable electromyographic activity was apparent, beginning at about $30-40 \mathrm{msec}$ after the stimulus. The shock was a single square wave fixed at $0.5 \mathrm{msec}$ duration. The average intensity was $2.7 \mathrm{~mA}$, and the range across subjects was 2.0-3.5 mA at the start. (On later trials, one subject required two increases in intensity, from 3.5 to 4.5 then to $6.5 \mathrm{~mA}$ to keep control responses in the appropriate range, and one subject required an increase from 3.0 to $3.5 \mathrm{~mA}$.)

Each subject received $\mathbf{4 2}$ trials, with a variable intertrial interval and no ready signal to warn them of a coming stimulus. There were seven stimuli in each of six conditions: the eliciting stimulus given alone, that is, without a preceding gap in the background, or preceded by a 10 -msec gap (with $\$ 1$-msec rise and decay times) with a lead time of $40,80,120,160$, or 200 msec. Trials were 20 $40 \mathrm{sec}$ apart and given in an order specified by $6 \times 6$ Latin square designs with one additional, seventh line. The orders were different for each subject. For the analysis of the ensuing data, the mean response voltages for each condition were normalized by setting each subject's grand total voltage equal to 100 , then apportioning percentage values of that total to each condition. The result is a "mean relative response amplitude."

\section{Results and Discussion}

The data for this experiment are given in Figure 1, which depicts the group mean relative response amplitude in each condition, as well as the means for each of the subjects. The brief gap in the noise inhibited the eyeblink reflex in all of the subjects, and all showed an increase in inhibition from 40 to $80 \mathrm{msec}$. The course of inhibition thereafter was somewhat diverse, although, for the group as a whole, it remained about constant for the next $120 \mathrm{msec}$. Analyses of variance of the grouped data yielded a reliable effect of conditions $[F(5,35)=19.55$, $\mathrm{p}<.01]$; as the graphed display makes obvious, the response at the 40-msec ISI was no different from the control value. Both of these values were reliably different from those obtained at $80-200 \mathrm{msec}$, which, in turn, were not systematically different from each other.

These data clearly show that this brief 10 -msec silent period in the white noise does affect a cutane-

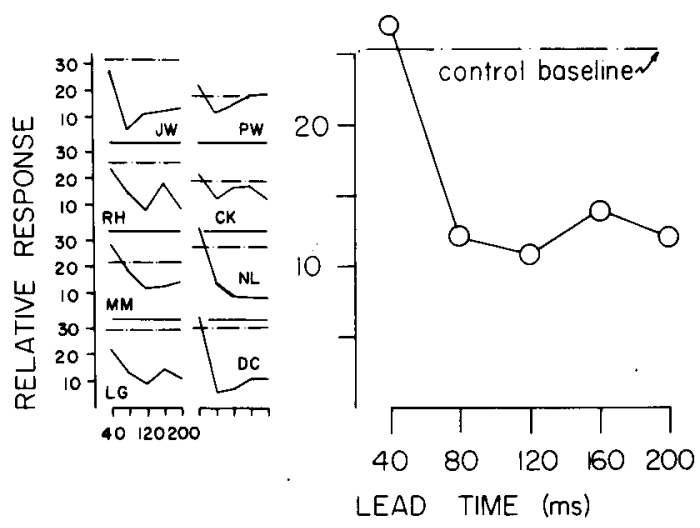

Figure 1. Relative response amplitude when the eliciting stimulus (S2) is presented alone (control value) and when $\mathbf{S 2}$ is preceded by a 10-msec silent period in white noise (S1) at the designated intervals between S1 and S2. On the left are the separate data from the eight subjects, and on the right, the group mean. 
ous eyeblink reflex elicited shortly thereafter, the temporal course of inhibition with changes in the interstimulus interval being about that seen in prior experiments. Although the strength of the inhibitory process varied across subjects, all showed some evidence $(p<.05)$ of reflex inhibition at the intermediate interstimulus intervals. It should be noted that the intensity of the eliciting stimulus was very low and all of the subjects appeared to ignore its presence after its first few presentations. Reflex inhibition did not change over the course of the experimental runs.

\section{EXPERIMENT 2}

In prior work with humans, we have found that reflex inhibition to noise pulses is reliably produced by stimulus intensities at or close to the psychophysical detection threshold and, furthermore, that the effectiveness of more intense stimuli was linearly related to their intensity in decibels (Reiter \& Ison, 1977 ) and to their duration in log seconds (Dykman \& Ison, 1979). In the following experiment, we first measured the threshold for gap detection using the method of limits. Then, at a fixed interstimulus interval of $100 \mathrm{msec}$, we varied the duration of the gap systematically through values below and above this threshold duration. The method of limits was used because it is a rapid and convenient test, a variant of the methods used extensively in conventional hearing tests. As one purpose of the present experiment is to suggest a method that might be useful in applied settings, this simple psychophysical procedure provided an appropriate comparison. The experiment allowed us to compare the amount of reflex inhibition provided by each of these durations of silence with the psychophysical judgments, as well as providing the quantitative relationship between reflex inhibition and gap duration.

\section{Method}

The subjects were 12 adult volunteers (11 women, 1 man) from the population used previously. Apparatus and procedural details were exactly the same as had been used before except that gap duration, rather than ISI, was varied. The gaps were $0,2,4,6,8$, and $10 \mathrm{msec}$ in duration, and the ISI was fixed at $100 \mathrm{msec}$. Each subject received 60 trials, 10 at each duration, the order of trials determined by two $6 \times 6$ Latin squares, one complete and one which contributed only its first four rows. (The orders were different from each subject). Prior to the reflex testing, each subject had 10 runs through the method of limits, with the gaps being raised or lowered in 1 -msec jumps and interstimulus intervals being 5 $10 \mathrm{sec}$. The subjects were told that they should tell us by saying "Yes" whenever they heard a perturbation in the noise, and they were given two or three examples. The stimuli were presented without any ready signal, although the subjects were informed before the beginning of the first run to attend to the noise and were told at the end of the last run that they could go back to their reading material. An ascending series stopped at the duration on which the subject detected the gap, and the descending series with the duration that was missed, the next series beginning $2.5 \mathrm{msec}$ beyond these stopping points. The transition values were averaged to give the "threshold." Reflex testing and the analysis of the data proceeded as before. For this group, the mean shock intensity at the beginning of testing was $4.3 \mathrm{~mA}$, and at the end, $5.4 \mathrm{~mA}$ (range 1.8-12 mA).

\section{Results and Discussion}

The data are given in Figure 2. On the left are the thresholds and the relative response amplitudes for the individuals, and on the right, the mean relative response amplitude and the mean detection threshold for the group. Detection thresholds varied from 4.3 to $6.2 \mathrm{msec}$ (mean $=5.4, \mathrm{SEM}=0.2$ ). These numbers compare reasonably with those in the literature, in which thresholds ranging from 3 to $10 \mathrm{msec}$ have been reported, depending on the intensity of the noise, the duration of the stimuli, the age of the subjects, and the method of testing [Davis \& McCroskey, 1980; Dooling, Zoloth, \& Baylis, 1978 (for the human subjects in this report); Penner, 1975; Perrott \& Williams, 1971; Plomp, 1964; Smiarowski \& Carhart, 1975; Williams \& Elfner, 1976; Williams, Elfner \& Howse, 1979]. Although there was again variation between the subjects in the inhibitory effectiveness of the gaps, each subject showed evidence of reliable $(p<.05)$ reflex inhibition at the intermediate and longer durations. Analysis of the grouped data yielded an overall effect of gap duration $[F(5,55)=24.38$, $\mathrm{p}<.011$, with significant linear and cubic trends $[F(1,11)=50.96,19.64, p<.01]$. Responses obtained following the 2-msec stimulus were no different from those in the 0 -msec control condition, and responses following the 8- and 10-msec stimuli were about of equal strength and inhibited by about $50 \%$. Between 2 and $8 \mathrm{msec}$, response amplitudes declined linearly with stimulus duration. These data are very similar to those previously found in rats (Ison, 1982), which showed a linear decrement in response amplitude as the duration of a preceding gap increased from 1 to $7 \mathrm{msec}$.

To examine the comparability of reflex inhibition and the detection thresholds provided by this simple

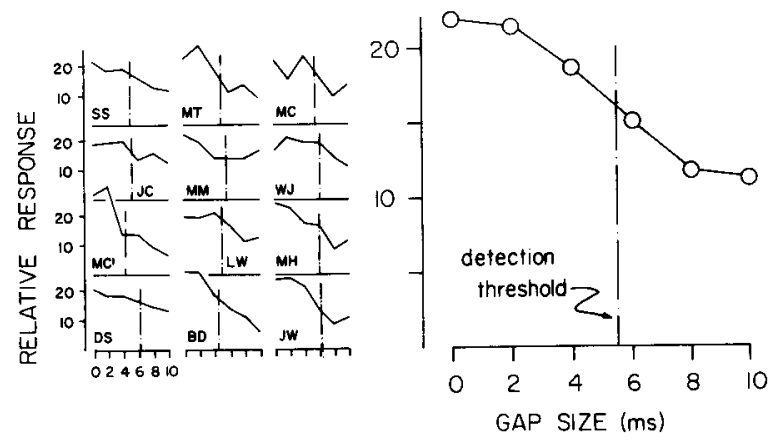

Figure 2. Relative response amplitude when the eliciting stimulus (S2) is preceded, at an ISI of 100 msec, by silent periods in white noise (S1) of the designated durations. On the left are the separate data from the 12 subjects, and on the right, the group mean. The threshold for $\mathrm{S1}$ detection determined by the method of limits is given by the broken vertical lines. 
psychophysical procedure, the slope of the individual inhibition functions over the 2-8-msec range was calculated, and this number was correlated with the detection threshold value. The correlation was -0.50 ( $p<.05$, one-tail), revealing the presence of a marginal relationship in which the more sensitive subjects had the steeper slopes. (The strength of this association may be limited in part by the unreliability in the two measures, as well as by their being affected by different variables.) For the group as a whole, the 4msec stimulus, which was below the detection threshold for even the most sensitive subject, had a significant influence on the subsequent reflex $(p<.05)$. A similar effect had been noted previously by Reiter and Ison (1977), who found that noise pips that were below the detection threshold exerted a small, but reliable, inhibitory effect on the group's mean eyeblink. The approximate comparability of the objective reflex measure and the measure provided by the method of limits is obvious if "inhibition threshold" were arbitrarily designated as the duration at which $50 \%$ of maximal inhibition was obtained: this yields a threshold of $5 \mathrm{msec}$ for the grouped data, which compares well with the mean detection threshold of $5.4 \mathrm{msec}$. The close comparison is especially noteworthy in that for the method of limits the subjects were fully alert and attentive to the stimuli, whereas during reflex testing they appeared to be engrossed in their reading material. As we have noted before (Reiter \& Ison, 1977), these data suggest that reflex inhibition is but little affected by attentional and decision processes that have considerable influence on the outcome of psychophysical procedures.

The shape of the inhibition function is of some interest. That it is approximately linear over time in the range of 2-8 msec suggests that there may be an underlying similar increment in intensity at stimulus onset following these different offset times, as we know that inhibition is linearly related to S1 intensity in decibels in other experiments of this same general sort when noise pips are used rather than gaps. If we assume that the effective variable in the gap experiment is the intensity change at onset (Plomp, 1964), then these data suggest that the resulting intensity change on the resumption of the noise may be approximately linearly related to the duration of silence in the range of $2-8 \mathrm{msec}$. The point here is not that the overall change in intensity as gap duration increases is linear, as opposed to some other function (i.e., an ogive), but that the major part of the change takes place over the course of this limited 6-msec range.

Finally, these data have considerable significance in underscoring the value of using the procedures of reflex modification as the empirical basis of objective behavioral tests of sensory function (Marsh, et al., 1978; Reiter, 1978, 1981; Russo, 1980; Young \& Fechter, 1983). It is apparent, as in earlier work with similar intent (Ison \& Adelson, 1979; Reiter \& Ison, 1977), that at least under some circumstances with human subjects reflex modification procedures yield indices of sensory sensitivity that are comparable to those offered by a conventional psychophysical method as it is used in clinical settings. It is true that, when one is dealing with articulate and compliant adults, this objective behavioral test takes longer than the voluntary response method. In the present series of experiments, for example, reflex testing took about $\mathbf{3 0} \mathrm{min}$, in contrast to only $5 \mathrm{~min}$ for the method of limits, and this difference does not count setup time for EMG recording, and so forth. But there are some populations for which the usual psychophysical methods seem inappropriate-children, for example, or persons with functional problems (Reiter, 1981; Reiter, Goetzinger, \& Press, 1981). For these populations, as with laboratory animals (Ison, 1982), reflex modification procedures may provide useful information about detection thresholds which is suitably close to the values that would be found by the conventional applied methods. Furthermore, it is obtained at not unreasonable cost in time, compared with those methods which use learned discriminative responses, and it does not depend on the patient's ability to learn about or attend to the test stimuli. These characteristics of the method suggest its value in the animal laboratory and in the clinic as an objective behavioral test of sensory function, an application that has been an early and a continuing concern of the investigators who have studied the basic phenomena of reflex modification (Ison \& Hoffman, 1983).

\section{REFERENCES}

Bowditch, H. P., \& Warren, J. W. The knee-jerk and its physiological modifications. Journal of Physiology, 1890, 11, $25-64$.

Cohen, L. H., Hilgard, E. R., \& Wendt, G. R. Sensitivity to light in a case of hysterical blindness studied by reinforcementinhibition and conditioning methods. Yale Journal of Biology and Medicine, 1933, 6, 61-67.

Davis, S. M., \& McCroskey, R. L. Auditory fusion in children. Child Development, 1980, 51, 75-80.

Dooling, R. J., ZoLoth, S. R., \& BaYlis, J. R. Auditory sensitivity, equal loudness, temporal resolving power, and vocalizations in the house finch (Carpodacus mexicanus). Journal of Comparative and Physiological Psychology, 1978, 92, 867-876.

Dyкman, B. M., \& Ison, J. R. Temporal integration of acoustic prestimulation and reflex inhibition in rats and humans. Journal of Comparative and Physiological Psychology, 1979, 93, 939-945.

GrahaM, F. K., \& MurRay, G. M. Discordant effects of weak prestimulation on magnitude and latency of the reflex blink. Physiological Psychology, 1977, 5, 108-114.

Graham, F. K., Putwam, L. E., \& LenvitT, L. A. Lead stimulation effects on human cardiac orienting and blink reflexes. Journal of Experimental Psychology: Human Perception and Performance, 1975, 1, 161-169.

Hilgard, E. R., \& Wendt, G. R. The problem of reflex sensitivity to light studied in a case of hemianopsia. Yale Journal of Biology and Medicine, 1933, 5, 373-385.

Hoffman, H. S., \& Ison, $\bar{J}$. $\overline{\mathbf{R}}$. Reflex modification in the domain of startle: I. Some empirical findings and their implica- 
tions for how the nervous system processes sensory input. Psychological Review, 1980, 87, 175-189.

Hoffman, H. S., \& Searle, J. L. Acoustic and temporal factors in the evocation of startle. Journal of the Acoustical Society of America, 1968, 43, 269-282.

Hoffman, H. S., \& STITT, C. L. Inhibition of the glabella reflex by monaural and binaural stimulation. Journal of Experimental Psychology: Human Perception and Performance, 1980, 6, 769-776.

Ison, J. R. Temporal acuity in auditory function in the rat: Reflex inhibition by brief gaps in noise. Journal of Comparative and Physiological Psychology, 1982, 96, 945-954.

Ison, J. R., \& Adelson, A. A. Reflex activity in orbicularis oculi following perioral tactile prestimulation in humans. Psychophysiology, 1979, 16, 201. (Abstract)

Ison, J. R., \& Hofrman, H. S. Reflex modification in the domain of startle: II. The anomalous history of a robust and ubiquitous phenomenon. Psychological Bulletin, 1983, 94, 3-17.

Ison, J. R., \& Pinckney, L. Reflex modulation in humans by monaural and binaural auditory stimulation. Bulletin of the Psychonomic Society, 1980, 15, 285-287.

Krauter, E. E., Leonard, D. W., \& Ison, J. R. Inhibition of the human blink by a brief acoustic stimulus. Journal of Comparative and Physiological Psychology, 1973, 84, 246-251.

LOMBARD, $W$. The variations of the normal knee-jerk and their relation to the activity of the central nervous system. American Journal of Psychology, 1887, 1, 5-17.

Marsh, R. R., Hoffman, H. S., \& Stitt, C. L. Eyeblink inhibition by monaural and binaural stimulation: One ear is better than two. Science, 1976, 192, 390-391.

Marsh, R. R., Hoffman, H. S., \& StitT, C. L. Reflex inhibition audiometry: A new objective procedure. Acta OtoLaryngology, 1978, 85, 335-341.

Penner, M. J. Persistence and integration: Two consequences of a sliding integrator. Perception \& Psychophysics, 1975, 18, 114-120.

Perrott, D. R., \& Williams, K. N. Auditory temporal resolution: Gap detection as a function of interpulse frequency disparity. Psychonomic Science, 1971, 25, 73-74.

Plomp, R. Rate of decay of auditory sensation. Journal of the Acoustical Society of America, 1964, 36, 277-282.
Reiter, L. A. Development and evaluation of reflex modification as an objective audiometric procedure. (Doctoral dissertation, University of Rochester, 1977). Dissertation Abstracts International, 1978, 39, 1988.

Reiter, L. A. Reflex modulation: A new method of measuring hearing in children. International Journal of Pediatric Otorhinolaryngology, 1981, 3, 79-84.

Reiter, L. A., Goetzinger, C. P., \& Press, S. E. Reflex modulation: A hearing test for the difficult-to-test. Journal of Speech and Hearing Disorders, 1981, 24, 262-266.

Reiter, L. A., \& Ison, J. R. Inhibition of the human eyeblink reflex: An examination of the Wendt-Yerkes method for threshold detection. Journal of Experimental Psychology: Human Perception and Performance, 1977, 3, 325-336.

Reiter, L. A., \& Ison, J. R. Reflex modulation and loudness recruitment. Journal of Auditory Research, 1979, 19, 201-207.

Russo, J. M. Sensation in the rat and mouse: Evaluation by reflex modification. (Doctoral dissertation, University of Rochester, 1979). Dissertation Abstracts International, 1980, 41, 392-B.

SANES, J. N., \& Ison, J. R. Conditioning auditory stimuli and the cutaneous eyeblink reflex in humans: Differential effects according to oligosynaptic or polysynaptic central pathways. Electroencephalography and Clinical Neurophysiology, 1979, 47,546-555.

Smianowski, R. A., \& CarharT, R. Relations among temporal resolution, forward masking, and simultaneous masking. Journal of the Acoustical Society of America, 1975, 57, 1169-1174

Williams, K. N., \& ElfNeR, L. F. Gap detection with three auditory events-a single channel process. Journal of the Acoustical Society of America, 1976, 60, 423-428.

Williams, K. N., Elfmer, L. F., \& Howse, W. R. Auditory temporal resolution: Effects of sensation level. Journal of Auditory Research, 1979, 19, 265-269.

Young, J. S., \& FechTER, L. D. Reflex inhibition procedures for animal audiometry: A technique for assessing ototoxicity. Journal of the Acoustical Society of America, 1983, 73, 1686-1693.

(Manuscript received November 22, 1982; revision accepted for publication March 15, 1983.) 